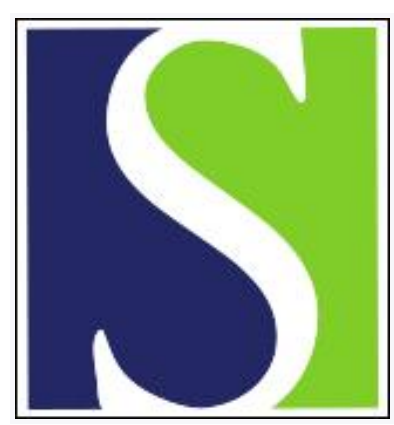

Scand J Work Environ Health 2001;27(5):346-352

https://doi.org/10.5271/sjweh.624

Issue date: Oct 2001

\title{
Vocational rehabilitation of workers with back pain
}

by Verbeek JHAM

Affiliation: Coronel Institute for Occupational and Environmental Health, Division of Public Health, Academic Medical Center, University of Amsterdam, PO Box 22660, 1100 DD Amsterdam, The Netherlands. j.h.verbeek@amc.uva.nl

Refers to the following texts of the Journal: 1995;21(1):3-14 1997;23(4):243-256 1999;25(1):50-56 1997;23(3):165-178 1998;24(5):358-366

Key terms: back pain; clinical practice guidelines; disability evaluation; discussion paper; occupational health physician; occupational health services; return to work; review; vocational rehabilitation; worker

This article in PubMed: www.ncbi.nlm.nih.gov/pubmed/11712616

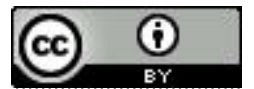




\title{
Vocational rehabilitation of workers with back pain
}

\author{
by Jos HAM Verbeek, PhD ${ }^{1}$
}

\begin{abstract}
Verbeek JHAM. Vocational rehabilitation of workers with back pain. Scand J Work Environ Health 2001;27(5):346352 .

This paper concerns the concepts and practices currently in use in occupational health for the rehabilitation of workers with back pain. No conclusive evidence exists for an etiologic model for nonspecific back pain. A difference between acute and chronic back pain is backed up by evidence from the literature. Apart from having the patient stay active and return to ordinary activities as early as possible, there are no significant forms of intervention for acute back pain that effectively decrease the time off work. For chronic back pain multidisciplinary treatment in an occupational setting is effective in enhancing return to work. Clinical practice guidelines consist of diagnostic triage, the assessment of "red flags" for medical emergencies, and guidance in the appropriate application of diagnostic facilities. Occupational health guidelines concentrate on gradual return to work, psychosocial issues, and multidisciplinary rehabilitation facilities.
\end{abstract}

Key terms clinical practice guidelines, disability evaluation, occupational health services, occupational health physician, return to work, review.

Virtually everyone has some extent of personal experience with pain or stiffness in their back. Not surprisingly, the lifetime prevalence of back pain is estimated to be as high as $57 \%$ of the general population (1). Acute back pain is inconvenient, but rarely an urgent medical problem, and for most people pain is gone within 6 weeks (2). For $10 \%$ to $30 \%$ of patients, however, back pain is not a transient experience; instead it returns frequently or is even present every day (3). In addition, in a large number of countries as many as $2 \%$ of all workers are so limited by back pain in their activities that they are out of work and receive a disability benefit (4). Those with chronic pain and disability place considerable demands on the health care and social security systems to help to solve their problem. These demands constitute an enormous burden for health care and the economy in most countries (5). The decade 2000-2010 has been proclaimed by the United Nations as the Joint and Bone Decade to draw attention to the problem of musculoskeletal disorders and, especially, back pain. ${ }^{2}$
In occupational health workers deal with both preventing the occurrence of back pain and preventing disability as a result of back pain. In this article I focus on the prevention of disability by means of rehabilitating workers with back pain. First, I give an overview of current concepts regarding the development of back pain. Next, I describe the assessment of a worker with back pain. A model is used to explain the process of disablement. Then I review the evidence for the effectiveness of different interventions and prognostic factors. Finally, I summarize current guidelines and end with pointing out future trends in back-pain rehabilitation.

\section{Development of back pain}

It remains one of the unsolved problems of health care and occupational health to find an appropriate answer to the back-pain problem. In the past, this search has often led to what Frank aptly calls "an unhelpful polemic"

1 Coronel Institute for Occupational and Environmental Health, Division of Public Health, Academic Medical Center, University of Amsterdam, Amsterdam, The Netherlands.

2 Information currently available at the following internet address: www.bonejointdecade.org

Reprint requests to: Dr Jos Verbeek, Coronel Institute for Occupational and Environmental Health, Division of Public Health, Academic Medical Center, University of Amsterdam, PO Box 22660, 1100 DD Amsterdam, The Netherlands. [E-mail: j.h.verbeek@amc.uva.nl] 
in musculoskeletal research (6). Persons with different views on the etiology of back pain very strongly advocate a single preventive measure or treatment method in line with their view of etiology. Basically, three different views can be discerned. First, some consider back pain to be the result of an injury caused by adverse workplace biomechanical exposure. Workplace redesign based on ergonomic principles is then the only remedy with which to treat and prevent back pain in their view (7).

Second, other researchers are more of the opinion that back pain is ubiquitous but that psychopathological conditions lead to disability (8). Their answer is the education and psychological treatment of workers. Finally, some authors argue that it is mostly the social context of dissatisfaction with work and the ready availability of workers' compensation and disability insurance benefits that is at the root of the back-pain disability problem (9). This view leads readily to the option of diminishing disability benefits or excluding back pain as a condition for which benefit payments can be received. At the base of this polemic is the lack of consensus about scientific evidence on the etiology of back pain and its associated disability.

A more productive assumption is that all back pain has a physical basis. Probably most attacks of back pain originate in the age-related degeneration of structures in the back. This degeneration is, in turn, influenced by mechanical, biochemical, and environmental risk factors (10-13); however the overall effect of these factors is probably limited (14). The experience of chronic pain and disability is influenced, at least partly, by psychosocial behavioral factors $(15,16)$. Nevertheless, much of the hypothesized causal pathway between exposure to environmental risk factors and occupational disability is still unknown.

\section{Assessment of workers with back pain}

Back pain is a symptom of an underlying physical process that cannot be diagnosed in most cases. In general practice, about $90 \%$ of all cases of back pain are diagnosed as nonspecific (17). After 2 weeks of sick leave in an occupational health setting, the percentage of cases diagnosed as nonspecific is $75 \%$ (18). Back pain can best be described as the perception of an unpleasant sensation in the brain, the origin of which is ascribed to the back (the part of the body between the horizontal line that can be drawn through the tips of the scapulae and the line through the gluteal folds). In addition, one of the features of back pain is that it can radiate into the buttocks and the legs.

For occupational health, back pain is best classified by a working diagnosis and duration. The classification derives its validity from the difference in prognosis, therapy, and return to work. There is increasing agreement that back pain is best classified into nonspecific back pain, sciatica, and specific back pain (19). Patients for whom it is not possible to attribute the back pain to a specific cause by means of usual clinical methods are diagnosed as having nonspecific back pain. A serious drawback of naming back pain this way is that it stresses the necessity of looking for a medical cause of the pain, with the danger of over using diagnostic facilities. For patients it would be more helpful to refer to nonspecific back pain as typical back pain, typical in the sense that back pain is common and a part of life, and such that many people experience it. Another 25\% of back-pain patients have sciatica characterized by symptoms in the leg, which suggest lumbosacral nerve root compromise. Specific back pain makes up less than $1 \%$ of all cases of back pain in a primary care setting (20). Specific back pain is a serious spinal condition caused by a tumor, an infection, a fracture, or a major neurological compromise such as the cauda equina syndrome. The following signs or symptoms are called red flags and possibly indicate serious spinal pathology: age younger than 20 or older than 50 years, violent trauma or minor trauma in a potentially osteoporotic patient, constant and progressive pain, history of carcinoma, systemically unwell, weight loss, risk factor for spinal infection such as infection elsewhere, intravenous drug abuse, use of steroids or immune suppression, and severe or progressive neurological deficit evident in a physical examination.

A great advantage of this classification is that simple history taking and a physical examination ensure the physician that there are no medical urgencies. Thereafter, the doctor can confidently outline a policy of rehabilitation and return to work. Moreover, it has been shown that patient satisfaction increases when providers have more confidence in their abilities to manage back pain effectively (21).

It is also generally agreed that it is useful to make a distinction between acute and chronic back pain. Acute back pain is usually a self-limiting condition and most workers with acute back pain return to work spontaneously (2). After a certain time period the chances that the pain will disappear spontaneously are much lower, and return to work is more difficult. The criterion for dividing pain into acute and chronic pain ranges in the literature from 4 weeks to 6 months according to the preference of the author (22-24). This variation emphasizes that the transition from acute pain to chronic pain is gradual, with an increasing risk of no return to work. From the rehabilitation point of view, it seems most efficient to use a criterion of 4 weeks for chronic pain.

There is not much support for classifying back pain into organic or somatic pain on the one hand and nonorganic or psychological pain on the other (25). It is 
impossible to experience pain without higher cerebral involvement, which is usually labeled psychological. Therefore, ultimately, all pain is "between the ears". Moreover, patients feel stigmatized by the label that their pain is "in their head", which is then not very helpful in therapy or rehabilitation. In all cases of back pain, whatever the cause, psychological mechanisms can hamper recovery or lead to chronic pain. Even though these mechanisms are not well understood, the following psychological factors are believed to be risk factors for chronic back pain: (i) attitudes and beliefs about back pain, such as the pain being harmful to the spine, (ii) inadequate illness behavior such as the use of extended rest, (iii) compensation issues, (iv) diagnosis and treatment leading to confusion or fear about outcome, (v) involvement of emotions, such as fear, irritation, low mood, (vi) belief that work is harmful, absence of interest of employer, no possibilities for gradual return to work or high biomechanical demands. These psychological risk factors are called yellow flags, comparable with the red flags for somatic risk factors (26).

\section{Disability model for back pain}

Researchers have argued that the outcome of treatment for back pain should be measured in more dimensions than merely the presence of pain (27). This is a useful approach because the problem of back pain is not determined only by pain alone but also, or even more so, by the patient's functioning and participation in society. The World Health Organization (WHO) has proposed a multidimensional model for the consequences of disease in the International Classification of Impairments, Disabilities and Handicaps (28). This model, which is used for description and communication, can also be helpful in understanding the dimensions of back pain problems (figure 1). It describes the consequences of a disorder in the following three different dimensions or levels: (i) a disease leads to impairments in body function or structure, (ii) impairments can subsequently lead to activity limitations experienced by an individual, and (iii) activity limitations can result in participation restrictions that a person may have in life situations such as work. The disease, as well as personal and environmental factors, influences the outcome at the different dimensional levels.

The rehabilitation process aims at maximizing the participation of the patient in his or her social setting $(29,30)$. It follows that not only medical intervention directed at eliminating disease or impairment is useful, but intervention aimed at improving environmental or personal conditions, which can then lead to less activity limitation or participation restriction, is also useful. It has been shown, for example, that work tempo and problematic relations with co-workers delay return to work (18). In addition, physiotherapy in the first 4 weeks has a worse outcome for return to work than advice by a general practitioner alone (31). At this time it is not possible, however, to fill in the model in a more quantitative way.

\section{Interventions}

A search in MEDLINE revealed that more than 2339 articles have been published about therapy for back pain since 1966. Intervention ranges widely from the application of sclerosing injections to the back (32) to the provision of an educational leaflet (33) and the use of magnetic radiation (34). Therefore, systematic reviews

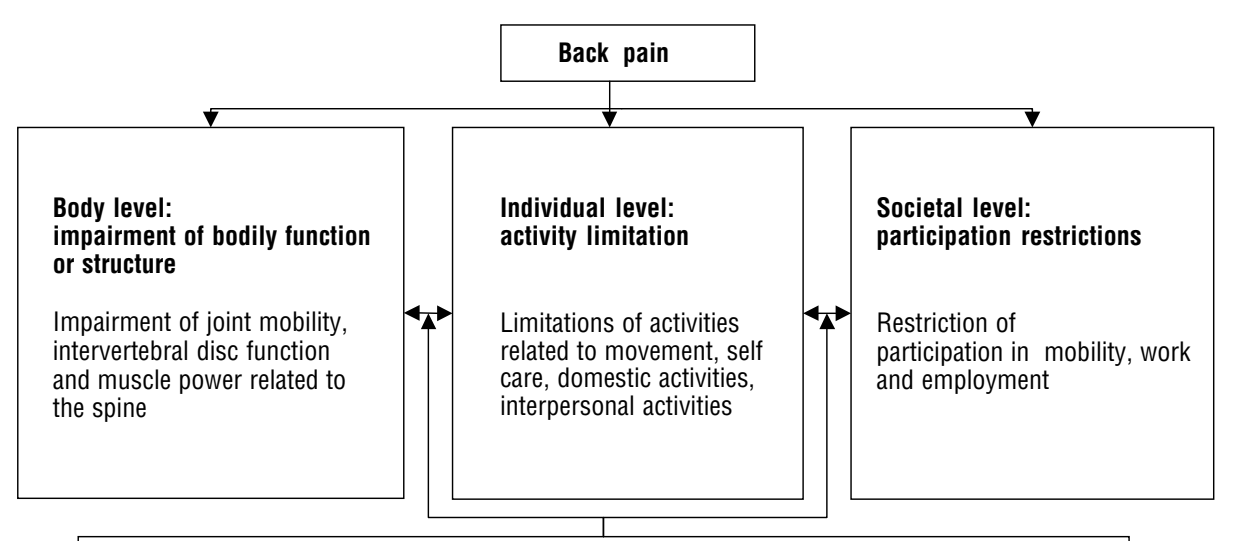

Environmental and personal factors:

environmental: vibration, heavy physical work, ergonomics organizational: support from colleagues and employer personal: individual attitudes, values and beliefs societal: societal attitudes, social norms, health services, social security system
Figure 1. A model of disability as a result of back pain according to the International Classification of Impairments, Disabilities, and Handicaps (ICIDH). 
are a great help in summarizing the evidence on the effectiveness of intervention. Van Tulder et al have done the most comprehensive work in this field. They gathered 208 studies on the effectiveness of conservative treatment for acute and chronic low-back pain (35) in combination with the Cochrane Collaboration Back Review Group for Spinal Disorders (36). The effectiveness of intervention is classified according to the evidence into one of the following four levels: strong, moderate, limited, absent or conflicting. The level of evidence for a specific intervention depends on the number, the methodological quality, and the results of randomized clinical trials that the participants of the review group found in the literature. The results of their study are summarized in tables 1 and 2.

It can be concluded that there is strong evidence for the effectiveness of nonsteroidal anti-inflammatory drugs, muscle relaxants, and advice to stay active in case of acute back pain. For chronic pain, strong evidence exists for the effectiveness of exercise therapy and multidisciplinary programs. However, a drawback of this review is that the different outcome dimensions of back pain, such as pain, activity limitation or participation restriction, are all valued equally. For rehabilitation purposes in occupational health a more appropriate outcome would be disability or the number of days on sick leave. Therefore Van der Weide et al (37) reviewed studies on intervention in low-back pain with at least one outcome in terms of disability or sick leave. Also in terms of vocational outcome, it can be concluded that staying active is to be preferred over bed rest. However, no studies were found which had a vocational outcome parameter that favored the effectiveness of drugs for acute back pain or the effectiveness of exercise therapy or multidisciplinary programs for chronic back pain.

\section{Prognosis of return to work}

Because acute back pain is such a highly prevalent problem, it would be interesting to know which patients run the highest risk of chronic pain and long-term disability. For the answer to this question, cohort studies are needed of workers who are at the same point in the course of their disease. For a prediction of the chances of return to work, such an inception cohort would consist of workers who are sick-listed because of back pain for less than 4 weeks. It can be concluded that chances of return to work are diminished if workers are older or if they have a higher level of initial disability, a specific diagnosis, or radiating pain $(18,38-41)$. From the same studies it can be inferred that heavy physical work does not predict time to return to work. There is a lack of evidence of the prognostic value for return to work

Table 1. Evidence for the effectiveness of conservative intervention for acute low-back pain based on systematic Cochrane reviews of the literature as reported by Van Tulder et al (35). ( $-=$ no randomized clinical trials found)

\begin{tabular}{|c|c|c|}
\hline Acute low-back pain & Intervention & $\begin{array}{l}\text { Evidence for } \\
\text { effectiveness }\end{array}$ \\
\hline Analgesics & $\begin{array}{l}\text { No more effective than nonsteroidal anti-inflammatory drugs } \\
\text { Less effective than electro-acupuncture or ultrasound }\end{array}$ & $\begin{array}{l}\text { Moderate } \\
\text { Limited }\end{array}$ \\
\hline Antidepressants & - & None \\
\hline Colchicine & No better than a placebo & Limited \\
\hline Muscle relaxants/benzodiazepine & Pain reduction better than a placebo & Strong \\
\hline Nonsteroidal anti-inflammatory drugs & $\begin{array}{l}\text { Better than a placebo } \\
\text { No better than paracetamol, opioids, muscle relaxants, } \\
\text { antidepressants, and nondrug treatment }\end{array}$ & $\begin{array}{l}\text { Strong } \\
\text { Conflicting }\end{array}$ \\
\hline Epidural steroid injections & Not effective & Moderate \\
\hline Facet joint injections & - & None \\
\hline Trigger point and ligamentous injections & - & None \\
\hline Acupuncture & - & None \\
\hline Advice to stay active & Better than bed rest or usual care & Strong \\
\hline Back schools & Better than other conservative treatment & Conflicting \\
\hline Bed rest & Worse than other conservative treatment or no treatment & Strong \\
\hline Behavioral therapy & Better than traditional care & Limited \\
\hline Electromyographic biofeedback & - & None \\
\hline Exercise therapy & No more effective than other treatment & Moderate \\
\hline Lumbar supports & - & None \\
\hline Multidisciplinary treatment programs & - & None \\
\hline $\begin{array}{l}\text { Physical agents and modalities (short wave } \\
\text { diathermy,ultrasound, ice, heat, massage) }\end{array}$ & - & None \\
\hline Spinal manipulation & Better than a placebo or other conservative treatment & Conflicting \\
\hline Traction & No better than a placebo or other conservative treatment & Moderate \\
\hline Transcutaneous electrical nerve stimulation (TENS) & Better than other conservative treatment & Conflicting \\
\hline
\end{tabular}


Table 2. Evidence for the effectiveness of conservative intervention for chronic low-back pain based on systematic Cochrane reviews of the literature as reported by Van Tulder et al (35). ( $-=$ no randomized clinical trials found)

\begin{tabular}{|c|c|c|}
\hline Chronic low-back pain & Intervention & $\begin{array}{l}\text { Evidence for } \\
\text { effectiveness }\end{array}$ \\
\hline Analgesics & Less effective than nonsteroidal anti-inflammatory drugs & $\begin{array}{l}\text { Limited } \\
\text { None }\end{array}$ \\
\hline Antidepressants & More effective than a placebo on pain relief & Conflicting \\
\hline Colchicine & No better than a placebo & Limited \\
\hline Muscle relaxants/benzodiazepine & Pain reduction better than a placebo & Limited \\
\hline Nonsteroidal anti-inflammatory drugs & $\begin{array}{l}\text { More effective than paracetamol and a placebo on overall } \\
\text { improvement and pain relief } \\
\text { Less effective than nonsteroidal anti-inflammatory drugs plus vitamin B }\end{array}$ & $\begin{array}{l}\text { None } \\
\text { Moderate } \\
\text { Moderate }\end{array}$ \\
\hline Epidural steroid injections & More pain relief than a placebo or anesthetic & Conflicting \\
\hline Facet joint injections & Not effective & Moderate \\
\hline Trigger point and ligamentous injections & Combination steroid and anesthetic better than anesthetic alone & Limited \\
\hline Acupuncture & No better than a placebo & Moderate \\
\hline Advice to stay active & - & None \\
\hline Back schools & $\begin{array}{l}\text { Better than no treatment in an occupational setting } \\
\text { Not better than other conservative treatment } \\
\text { Better than no treatment or a placebo in nonoccupational settings }\end{array}$ & $\begin{array}{l}\text { Moderate } \\
\text { Moderate } \\
\text { Conflicting }\end{array}$ \\
\hline Bed rest & - & None \\
\hline Behavioral therapy & $\begin{array}{l}\text { Better than no treatment in reducing pain and disability } \\
\text { Better than other conservative treatment }\end{array}$ & $\begin{array}{l}\text { Moderate } \\
\text { Conflicting }\end{array}$ \\
\hline Electromyographic biofeedback & No more effective than a placebo or relaxation & Moderate \\
\hline Exercise therapy & $\begin{array}{l}\text { Equally effective as physiotherapy } \\
\text { More effective than usual care by a general practitioner }\end{array}$ & $\begin{array}{l}\text { Strong } \\
\text { Strong }\end{array}$ \\
\hline Lumbar supports & - & None \\
\hline Multidisciplinary treatment programs & Better than traditional case in patient rehabilitation or usual care & Strong \\
\hline $\begin{array}{l}\text { Physical agents and modalities (short wave } \\
\text { diathermy, ultrasound, ice, heat, massage) }\end{array}$ & - & None \\
\hline Spinal manipulation & Better than a placebo or other conservative treatment & Conflicting \\
\hline Traction & Not better than a placebo or other conservative treatment & Strong \\
\hline Transcutaneous electrical nerve stimulation (TENS) & Better than a placebo or other conservative treatment & Conflicting \\
\hline
\end{tabular}

for psychosocial factors and work conditions in general. For a cohort of workers on sick leave of up to 8 weeks' duration, Waddell's nonorganic signs predicted a delayed return to work (42).

\section{Guidelines for managing low-back pain at work}

Since the beginning of the 1990s, following the report of the Quebec Task Force on Low Back Pain, guidelines on the management of low-back pain in primary care situations have been developed in many countries (22, 24, 43-45). The aim of the guidelines is the restoration to normal functioning for patients with back pain. However, for most of these patients occupational factors are only mentioned superficially. Recently, evidence-based guidelines have been developed for the management of workers with back pain in occupational health $(46,47)$. In addition to clinical management, these guidelines provide more-detailed recommendations on return to work and active rehabilitation. When a worker with back pain sees an occupational health practitioner, the worker should be encouraged to continue as nor- mally as possible. He or she should remain at work or return to work at an early stage even if he still has some back pain. A temporary adaptation of the job or pattern of work is advised to facilitate early return to work (48). The guidelines recommend active rehabilitation and return to work strategies if the worker is having difficulty returning to normal occupational duties after 4 to 12 weeks of back pain or sickness absence. Then the focus should be shifted from purely symptomatic treatment to an active rehabilitation program in an occupational setting. A combination of optimum clinical management, a rehabilitation program, and organizational intervention to assist the worker to return to work is thought to be the most effective. The rehabilitation program should contain education, reassurance and advice to stay active, graded exercises, and behavioral pain management. It should be carried out in an occupational setting and directed towards return to work.

\section{Future developments}

We are highly dependent on systematic literature reviews to synthesize evidence on aspects of the back-pain 
problem. The methodology of systematic reviews is not yet very sophisticated. On many occasions, we have to rely on simply adding up the number of studies with positive and negative results to come to a conclusion. In the future, better empirical studies and better synthesis methods will improve systematic reviews and metaanalyses that will lead to new recommendations and guidelines.

Current guidelines, most of which have been recently introduced, aim at reducing the number of people with chronic pain and disability. Research shows that considerable change is needed to implement the guidelines fully $(49,50)$, but also that the availability of recommended back pain services increased after the introduction of guidelines in the United Kingdom (51). Therefore, we can expect that, as guidelines become better implemented, the number of people with chronic pain and disability will decrease.

Rehabilitation methods will improve with a better understanding of psychological mechanisms leading to chronic pain behavior, such as fear-avoidance beliefs (52). Evaluation studies will learn which components of rehabilitation programs are most effective and appropriate for the primary care and occupational health setting.

In the more distant future, progress can be expected from a better understanding of the process of degeneration of the spine, the development of back pain and pain behavior. Magnetic resonance imaging of the spine will become more widely available and may contribute to clarifying the process of spine degeneration (53). The assessment of metabolic processes in patients with heavy physical load or back pain may be developed into another measure of objective assessment of damage to the cartilage of the spine (54). Some studies suggest that these measurements can also be used to monitor outcome in rehabilitation objectively (55). Nevertheless, vocational rehabilitation will remain one of the cornerstones of back-pain management because we are still far from the time that treatment can be directed towards the causes of back pain.

\section{Acknowledgments}

I thank my colleagues from the Department of Research and Development in Occupational Health Services at the Finnish Institute of Occupational Health for their hospitality, which made it possible to write this review.

\section{References}

1. Haanen HCM. Een epidemiologisch onderzoek naar lage rugpijn [Epidemiological study into low back pain] [disserta- tion]. Rotterdam (The Netherlands): Erasmus University of Rotterdam, 1984.

2. Coste J, Delecoeuillerie G, Cohen de LA, LeParc JM, Paolaggi JB. Clinical course and prognostic factors in acute lowback pain: an inception cohort study in primary care practice. BMJ 1994;308:577-80.

3. Thomas E, Silman AJ, Croft PR, Papageorgiou AC, Jayson MIV, Macfarlane GJ. Predicting who develops chronic lowback pain in primary care: a prospective study. BMJ 1999;318:1662-7.

4. Verbeek JHAM. Arbeidsongeschiktheid als gevolg van aandoeningen van het bewegingsapparaat. [Disability as a result of musculoskeletal disorders]. Tijdschr Soc Gezondheidszorgan 1987;65:562-6.

5. Van Tulder MW, Koes BW, Bouter LM. A cost-of-illness study of back pain in the Netherlands. Pain 1995;62:233-40.

6. Frank JW, Pulcins IR, Kerr MS, Shannon HS, Stansfeld SA. Occupational back pain - an unhelpful polemic [review]. Scand J Work Environ Health 1995;21:3-14.

7. Ayoub MA. Ergonomic deficiencies: I. Pain at work. J Occup Med 1990;32:52-7.

8. Fordyce WE, editor. Back pain in the workplace: management of disability in non-specific conditions. Seattle (WA): IASP press, 1995.

9. Hadler NM. Disabling backache in France, Switzerland and the Netherlands: contrasting socio-political constraints on clinical judgement. J Occup Med 1989;31:823-31.

10. Hadjipavlou AG, Simmons JW, Pope MH, Necessary JT, Goel VK. Pathomechanics and clinical relevance of disc degeneration and annular tear: a point-of-view review. Am J Orthop 1999;28:561-71.

11. Bovenzi M, Hulshof CTJ. An updated review of epidemiologic studies on the relationship between exposure to wholebody vibration and LBP (19860-1997). Int Arch Occup Environ Health 1999;72:351-65.

12. Kuiper JI, Burdorf A, Verbeek JHAM, Frings-Dresen MHW, van der Beek AJ, Viikari-Juntura ERA. Epidemiologic evidence on manual materials handling as a risk factor for back disorders: a systematic review. Ind Ergon 1999;24:389-404.

13. Burdorf A, Sorock G. Positive and negative evidence of risk factors for back disorders [review]. Scand J Work Environ Health 1997;23:243-56.

14. Videman T, Battie MC. The influence of occupation on lumbar disc degeneration. Spine 1999;21:1164-8.

15. Crombez G, Vlaeyen JW, Heuts PH, Lysens R. Pain-related fear is more disabling than pain itself: evidence on the role of pain-related fear in chronic back pain disability. Pain 1999;80:329-39.

16. Burton AK. Back injury and work loss: biomechanical and psychosocial influences. Spine 1997;22:2575-80.

17. Lamberts H. In het huis van de huisarts. [In the house of the general practitioner]. Lelystad: Meditekst, 1991.

18. van der Weide WE, Verbeek JHAM, Sallé HJA, van Dijk FJH. Prognostic factors for chronic disability from acute lowback pain in occupational health care. Scand J Work Environ Health 1999;25:50-6.

19. Deyo RA, Weinstein JN. Low back pain. N Engl J Med 2001;344:363-70

20. Roland M, Morris R. A study of the natural history of low back pain. Spine 1983;8:145-50.

21. Bush T, Cherkin D, Barlow W. The impact of physician attitudes on patient satisfaction with care for low back pain. Arch Fam Med 1993;2:301-5

22. Bigos S, Bowyer O, Braen G, Brown KC, Deyo RA, 
Haldeman S. Acute low-back problems in adults: clinical practice guideline nr 14. Rockville (MD): United States Department of Health and Human Services, Public Health Service, Agency for Health Care Policy and Research, 1994.

23. Spitzer WO, LeBlanc FE, Dupuis M. Scientific approach to the assessment and management of activity-related spinal disorders: a monograph for clinicians, report of the Quebec Task Force on spinal disorders. Spine1987;12:s1-s59.

24. Accident Rehabilitation and Compensation Insurance Corporation(ACC) and the National Health Committee. New Zealand acute low back pain guide. Wellington (NZ): ACC, 1997.

25. Main CJ, Waddell G. Behavioural responses to examination: a reappraisal of the interpretation of 'Non-organic signs'. Spine 1998;23:2367-71.

26. Kendall NAS, Linton SJ, Main CJ. Guide to assessing psychosocial yellow flags in acute low back pain: risk factors for long-term disability and work loss. Wellington (NZ): Accident Rehabilitation \& Compensation Insurance Corporation of New Zealand and the National Health Committee, 1997.

27. Deyo RA, Battie M, Beurskens AJHM, Bombardier C, Croft $\mathrm{P}$, Koes B, et al. Outcome measures for low back pain research: a proposal for standardized use. Spine 1998;23:2003-13.

28. World Health Organisation (WHO). Towards a common language for functioning and disablement: ICIDH-2, the International Classification of Impairments, Activities, and Participation. Geneva: WHO, 1998.

29. Frank A. Rehabilitation medicine. BMJ 1998;317:14.

30. Wade DT, de Jong BA. Recent advances in rehabilitation. BMJ 2000;320:1385-8.

31. Faas A, van Eijk JTM, Chavannes AW, Gubbels JW. A randomised trial of exercise therapy in patients with acute low back pain: efficacy on sickness absence. Spine 1995;20:941-7.

32. Dechow E, Davies RK, Carr AJ, Thompson PW. A randomized, double-blind, placebo-controlled trial of sclerosing injections in patients with chronic low back pain. Rheumatology (Oxford) 1999;38:1255-9.

33. Burton AK, Waddell G, Tillotson KM, Summerton N. Information and advice to patients with back pain can have a positive effect. A randomized controlled trial of a novel educational booklet in primary care. Spine 1999;24:2484-91.

34. Collacott EA, Zimmerman JT, White DW, Rindone JP. Bipolar permanent magnets for the treatment of chronic low back pain: a pilot study. JAMA 2000;283:1322-5.

35. Van Tulder MW, Koes BW, Assendelft WJJ, Bouter LM. The effectiveness of conservative treatment of acute and chronic low back pain. Amsterdam: EMGO-institute, Faculty of Medicine Vrije Universiteit, 1999.

36. Bombardier C, Esmail R, Nachemson AL. The Cochrane back review group for spinal disorders. Spine 1997;22:837-40.

37. Van der Weide WE, Verbeek JHAM, van Tulder MW. Vocational outcome of intervention for low-back pain [review]. Scand J Work Environ Health 1997;23:165-78.

38. Infante-Rivard C, Lortie M. Prognostic factors for return to work after a first compensated episode of back pain. Occup Environ Med 1996;53:488-94.

39. Abenhaim L, Rossignol M, Gobeille D, Bonvalot Y, Fines P, Scott $\mathrm{S}$. The prognostic consequences in the making of the initial medical diagnosis of work-related back injuries. Spine 1995;20:791-5.
40. Goertz MN. Prognostic indicators for acute low-back pain. Spine 1990;15:1307-10.

41. Lehman TR, Spratt KF, Lehman KK. Predicting long-term disability in low back injured workers presenting to a spine consultant. Spine 1993;18:1103-12.

42. Gaines WG, Hegmann KT. Effectiveness of Waddell's nonorganic signs in predicting a delayed return to regular work in patients experiencing acute occupational low back pain. Spine 1999;24:396-401.

43. Royal College of General Practitioners (RCGP). Clinical guidelines for the management of acute low back pain. London: RCGP, 1999.

44. Faas A, Chavannes AW, Koes BW, van den Hoogen JMM, Mens JMA, Smeele LJM, et al. NHG standaard lage rugpijn [Dutch college of general practitioners practice guideline for low back pain]. Huisarts Wet 1996;39:18-31.

45. Smeele IJM, van den Hoogen JMM, Mens JMA, Chavannes AW, Faas A, Koes BW, et al. NHG standaard lumbosacraal radiculair syndroom [Dutch college of general practitioners practice guideline sciatica]. Huisarts Wet 1996;39:78-89.

46. Aulman P, Bakker-Rens RM, Dielemans SF, Mulder A, Verbeek JHAM. Het handelen van de bedrijfsarts bij werknemers met lage rugklachten [Practice guideline for occupational physicians: workers with low back pain]. Eindhoven (The Netherlands): Nederlandse Vereniging voor Arbeids- en Bedrijfsgeneeskunde (NVAB), 1999.

47. Carter JT, Birrell LN, editors. Occupational health guidelines for the management of low back pain at work - principal recommendations. London: Faculty of Occupational Medicine, Royal College of Medicine, 2000.

48. Krause N, Dsinger LK, Neuhauser F. Modified work and return to work: a review of the literature. J Occup Rehabil 1998;8:113-39.

49. Little P, Smith L, Cantrell T, Chapman J, Langridge J, Pickering R. General practitioners' management of acute back pain: a survey of reported practice compared with clinical guidelines. BMJ 1996;312:485-8.

50. Van der Weide WE, Verbeek JHAM, van Dijk FJH, Doef F. An audit of occupational health care for employees with lowback pain. Occup Med 1997;47:294-300.

51. Barnett AG, Underwood MR, Vickers MR. Effect of UK national guidelines on services to treat patients with acute low-back pain: follow-up questionnaire survey. BMJ 1999;318:919-20.

52. Vendrig AA. Prognostic factors and treatment-related changes associated with return to work in the multimodal treatment of chronic back pain. J Behav Med 1999;22:217-32.

53. Luoma K, Riihimäki H, Raininko R, Luukkonen R, Lamminen A, Viikari-Juntura E. Lumbar disc degeneration in relation to occupation. Scand J Work Environ Health 1998;24:358-66.

54. Kuiper JI, Verbeek JHAM, Frings-Dresen MHW, Klein Ikkink AJ. Keratan sulfate as a potential biomarker of loading of the intervertebral disc. Spine 1998;23:657-63.

55. Hupli M, Hurri H, Luoto S, Risteli L, Vanharanta H, Risteli J. Low synthesis rate of type 1 procollagen is normalised during active back rehabilitation. Spine 1997;22:850-4.

Received for publication: 19 March 2001 